\title{
Systematics and faunistics of Neotropical Euliina, 1: \\ Chamelania RAZOWSKI, 2001 and Unaica gen. n. (Lepidoptera: Tortricidae: Cochylini)
}

\author{
JÓZEF RAZOWSKI $^{1 *}$, VITOR OSMAR BECKER $^{2}$ \\ ${ }^{1}$ Institute of Systematics and Evolution of Animals, Polish Academy of Sciences, \\ Sławkowska 17, 31-016 Kraków, Poland \\ ${ }^{2}$ Reserve Serra Bonita, P.O. Box 01, 45880 Camacan, BA, Brazil
}

\begin{abstract}
One genus, Unaica gen. n., and seven species (Unaica plumbea sp. n., Chamelania acaena sp. n., Chamelania celyphana sp. n., Chamelania corumbae sp. n., Chamelania lutea sp. n., Chamelania quasirufa sp. n., Chamelania belemana sp. n.) are described and illustrated. Chamelania is redescribed and two of its species, Chamelania jaliscana and Chamelania auricoma, are listed. Lophoderus xanthophilanus WALKER, 1863 is transferred to Chamelania. Notes on Odonthalitus RAZOWSKI, 1991 and an illustration of the male genitalia of $O$. poas BROWN, 2000 are included.
\end{abstract}

KEY WORDS: Euliina, Cochylini, Tortricidae, new genus, new species, Neotropics.

\section{INTRODUCTION}

The paper deals with one originally monotypic genus. Here, we add five new species to Chamelania RAZOWSKI, 2001, amending and complementing its description. The number of species in other tortricid genera, chiefly from the Neotropical and Afrotropical regions, has increased significantly. The systematic position of Unaica is obscure and the lack of a female prevents a more meaningful interpretation of the phylogenetic position of this genus, hitherto based only on external similarities.

\footnotetext{
*Corresponding author: Razowski@isez.pan.krakow.pl
} 


\section{MATERIALS}

The specimens examined for this paper were collected by the second author. The types of the newly described species are deposited in the Becker collection, Camacan, Brazil, and will eventually be deposited in one of the major Brazilian Museums. A few specimens have been kindly donated to the Institute of Systematics and Evolution of Animals, Polish Academy of Sciences.

Note. The numbers cited from the specimen labels are the entry numbers in the register book of the second author.

Abbreviations used: GS - genitalia slide, VOBC - V.O. BECKER Collection, ISEZ - Institute of Systematics and Evolution of Animals, Polish Academy of Sciences, NHML - Natural History Museum London, NMHN - National Museum of Natural History, Washington.

\section{RESULTS}

\section{Unaica gen. $\mathbf{n}$.}

Type-species: Unaica plumbea sp. n.

\section{Diagnosis}

In facies, Unaica differs from all known euliine genera and resembles several species of Acleris HÜBNER, 1825 and Polyortha DOGNIN, 1905. In the genitalia it resembles Ernocornutia RAZOWSKI, 1988, Euliina but differs in the unique terminal spine on the sacculus.

\section{Description}

Male genitalia. Tegumen broad, short, with large ventrolateral lobes posteriorly; uncus short, broad basally, tapering terminad; socius well sclerotized, slender in posterior half; gnathos a broad transverse sclerite; valva elongate with dorsum better sclerotized than ventral concave part, and convex caudal edge; sacculus long, broad to middle, concave in distal part, where weakly serrate ventrally, terminating in two processes, the dorsal one of which bears two spines; phallus moderately slender, convex ventroterminally; numerous microspinulae in posterior part of vesica and elongate proximal sclerite.

\section{Distribution and biology}

Unaica is known from Paraná and Minas Gerais, southern and Central Brazil, respectively. It was collected in May, June and September at altitudes of 700 and $800 \mathrm{~m}$. 


\section{Etymology}

The name refers to Unai, the paratype locality of the type species.

\section{Remarks}

Unaica is described as a monotypic genus but has at least one unnamed Central American species (in the collection of the United States National Museum, genitalia on slide 68616) with similar male genitalia.

\section{Unaica plumbea sp. n.}

(Figs 1, 2, 20)

\section{Diagnosis}

Unaica plumbea is the only species of the genus. In facies, it resembles dark forms of the Brazilian Biclonuncaria alota RAZOWSKI \& BECKER, 1993, Polyorthini. The male genitalia are highly distinct, but the female is unknown.

\section{Description}

Wing span $18 \mathrm{~mm}$. Head and thorax brownish, thorax dark brown, labial palpus cream brown. Forewing uniformly broad throughout; apex broad; median part of termen straight. Ground colour brownish, traces of markings brown; rows of appressed black-brown scales in oblique rows; subapical marking diffuse reaching end of termen, also spotted brown. Cilia brownish with brown-black terminations. Hindwing dark brown; cilia brown-grey.

Male genitalia (Fig. 1, 2) and female genitalia (Fig. 14) as described for the genus.

\section{Material examined}

Holotype male: "Banhado, Quatro Barras, P[a]R[ana], 800 m, 9. VI. 1970, V.O. BECKER leg; V.O. BECKER col”; VOBC 49366; GS 6140. Paratypes: one identically labelled male; one male from Unai, Minas Gerais, 700 m, 27. IX. 1983, GS 21967.

\section{Etymology}

The specific name refers the colouration of forewing; Latin: plumbeus - a leaden colour.

\section{Chamelania RAZOWSKI, 2001}

Chamelania RAZOWSKI, 2001, SHILAP Revta Lepid., 29(115): 276. Type species: Chamelania jaliscana RAZOWSKI, 2001, Jalisco, Mexico. 

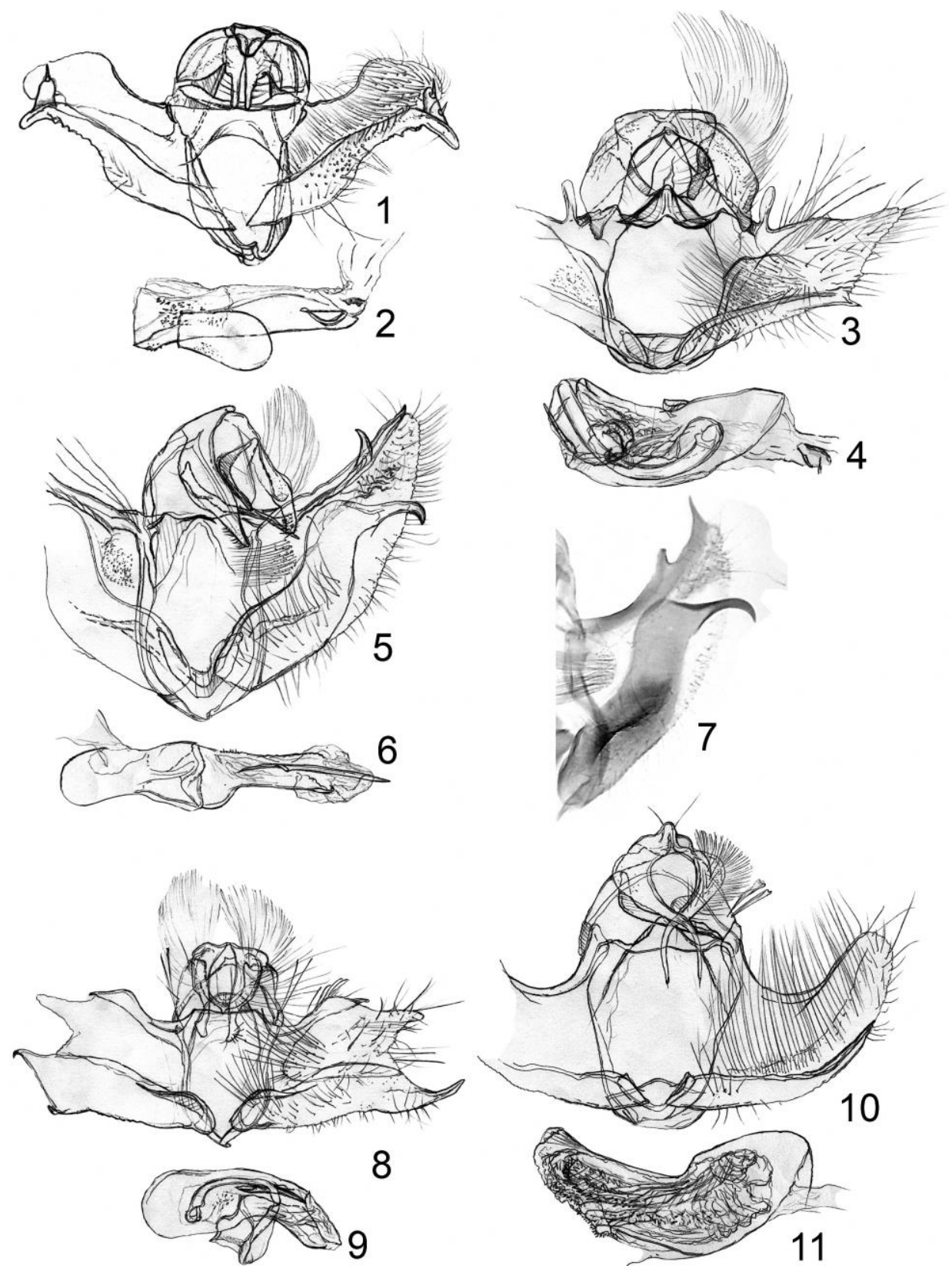

Figs 1-11. Male genitalia: 1, 2-Unaica plumbea sp. n., holotype; 3, 4-Chamelania acaena sp. n., holotype; 5, 6-Chamelania celyphana sp. n., holotype; 7 - same species, valva of paratype, GS 387; 8, 9 - Chamelania lutea sp. n., holotype; 10, 11 - Chamelania belemana sp. n., holotype. 


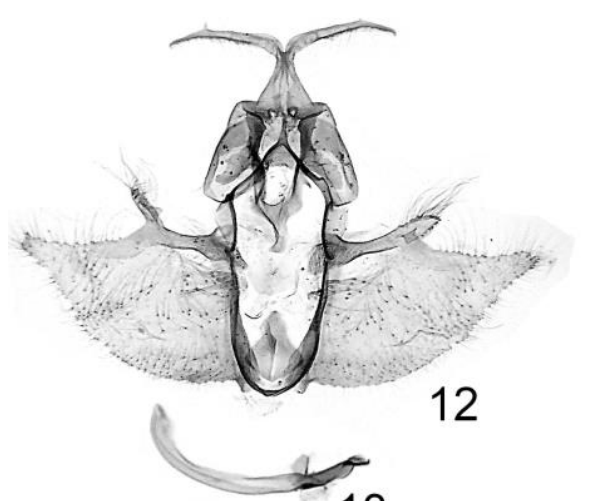

13

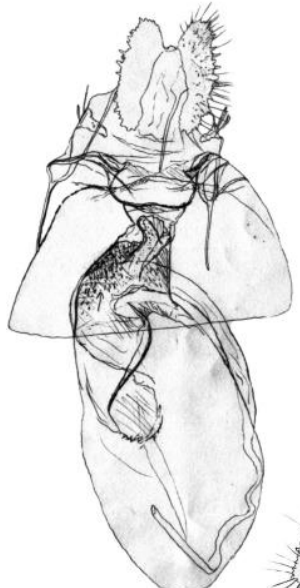

15

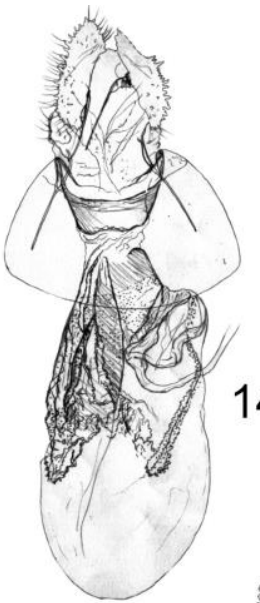

14

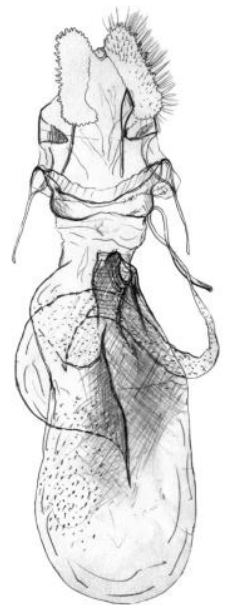

17

18

Figs 12-19. Male and female genitalia: 12, 13 - Odonthalitus poas BROwn, 2000, Turrialba, Costa Rica; 14 - Chamelania acaena sp. n., paratype; 15 - Chamelania lutea sp. n., paratype; 16 - Chamelania quasirufa sp. n., holotype; 17 - Chamelania belemana sp. n., paratype; 18 - Chamelania xanthophilana (WALKER, 1863), holotype; 19 - Chamelania corumbae sp. n., holotype. 

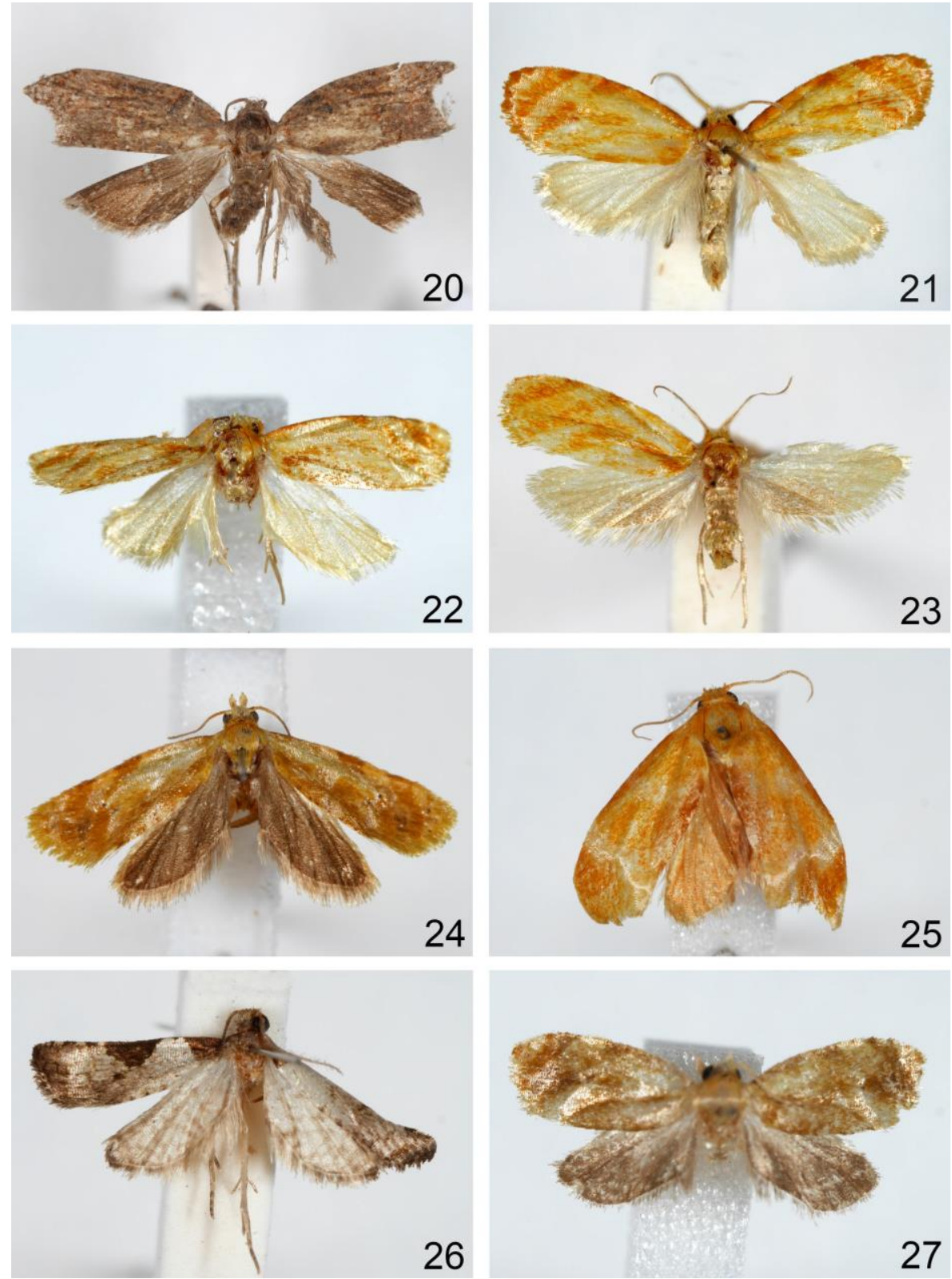

Figs 20-27. Adults: 20 - Unaica plumbea sp. n., paratype; 21 - Chamelania acaena sp. n., paratype; 22 - Chamelania celyphana sp. n., paratype, GS 388; 23 - Chamelania lutea sp. n., paratype; 24 - Chamelania quasirufa sp. n., holotype; 25- Chamelania belemana sp. n., paratype, GS 390; 26 - Odonthalitus poas BROWN, 2000, Turrialba, Costa Rica; 27 - Chamelania corumbae sp. n., holotype. 


\title{
Remarks
}

Chamelania was erected as a monotypic genus. RAZOWSKI (2000) described C. jaliscana from Mexico and RAZOwSKI \& Pelz (2003) described C. auricoma from Morona-Santiago Province, Ecuador. In this paper five new Brazilian species are described. Based on those species, we can now give this improved description.

The shape of the wings is constant; the forewing ground colour is mostly yellow, the markings are orange to rust orange, in three species the dorsum is concolorously suffused (or a triangular blotch develops). In the male genitalia the uncus is rudimentary or completely reduced; the socii are large, tapering terminally or subterminally, long and hairy or with some distal microspines; the arms of the gnathos are slender, usually with a strong terminal plate (reduced in C. lutea); the transtilla is variable - in some species it is simple, in others the median part is developed; the costa of the valva has median and terminal processes, but the median is absent in C. celyphana and C. lutea, the terminal is completely reduced in acaena and auricoma, and both processes are absent in C. belemana. The sacculus has a terminal process; the caudal edge of the valva is rounded or triangularly extended; the phallus is usually broad; there are two cornuti, one strongly curved (absent in C. celyphana and C. belemana) and the other short and spiniform; both cornuti are absent in $C$. belemana, and are quite different and short in C. auricoma.

Female genitalia are mostly constant with more or less large sclerites in the bursa copulatrix, the posterior of which forms a convexity. The base of the ductus seminalis is usually broad, originating in the median or postmedian part of the corpus bursae. Only in $C$. auricoma and $C$. xanthophilana are there two strongly spined sclerites of the bursa copulatrix and a simple base of the ductus seminalis.

Chamelania is distributed from Mexico to Paraná and Belém in Brazil and Ecuador. Nothing is known of the biology of the species except for the dates of collection. They occur at least in two generations per year at altitudes of $40-1000 \mathrm{~m}$.

\section{Chamelania jaliscana RAZOWSKI, 2001}

\author{
Material examined \\ One male from Campeche Escargera, Mexico, 17-21. VI. 1981; GS 21670.
}

\section{Distribution}

C. jaliscana is an exclusively Mexican species, now recorded from Jalisco and Campeche. 


\section{Chamelania acaena sp. $\mathbf{n}$.}

(Figs 3, 4, 14, 21)

\section{Diagnosis}

C. acaena resembles $C$. jaliscana but the latter has a broader forewing and a process at the end of the costa of the valva that is absent in C. jaliscana.

\section{Description}

Wing span $12 \mathrm{~mm}$. Head creamish, thorax yellow cream, pale orange anteriorly. Forewing not expanding terminally; costa weakly convex. Ground colour yellow. Markings pale orange consisting of dorsal and median longitudinal markings and two oblique fasciae, median and subterminal. Cilia cream with orange parts. Hindwing cream, mixed orange on peripheries. Cilia cream tinged orange.

Male genitalia (Figs 3, 4). Uncus rudimentary; socius large, broad except for small, laterally serrate terminal part; terminal plate of gnathos broad to beyond middle, pointed apically; costa of valva with strong, digitate postbasal process lacking terminal process; caudal part elongate triangular; sacculus slender, with sharp free terminal projection; median part of juxta large, triangular; phallus large, broad; one cornutus free, the second short, straight, slender.

Female genitalia (Fig. 14). Anteostial sterigma large, straight proximally; posterior part of ductus bursae short, membranous; sclerites of ventral part elongate, spined, reaching beyond middle of corpus bursae. Ductus seminalis postmedian.

\section{Material examined}

Holotype male: "Planaltina, D[istrito]F[ederal], 1000 m, 15. IV. 1985, V.O. BECKER col; Col BECKER 57414"; GS 22280; eight paratypes labelled as above but dated 15. III. 1985, 3. IV. 1984; 13. I. 1983 and 18. XII. 1982; one female from Vilhena, $600 \mathrm{~m}$, Rondonia, 10-13. IV. 1976, VOBC 107132; and one female from Rio Brilhante, Mato Grosso, 15. I. 1971, GS 21560.

\section{Etymology}

The specific epithet refers the sharp valval processes; from the Greek - akaina, a thorn. 


\section{Chamelania celyphana sp. $\mathbf{n}$.}

(Figs 5-7, 22)

\section{Diagnosis}

In facies, $C$. celyphana is similar to $C$. jaliscana. The male genitalia of $C$. celyphana are distinguished by the absence of the median process of the transtilla and the large, curved cornutus, and a strongly curved sacculus.

\section{Description}

Wing span $11 \mathrm{~mm}$. Head and thorax cream, the latter orange proximally. Forewing slightly expanding terminally; costa indistinctly convex; termen hardly convex. Ground colour yellowish cream with glossy pearl fasciae. Suffusions more orange; markings pale reddish orange, diffuse. Dorsobasal fascia slender; median fascia interrupted subcostally and postmedially accompanied by diffuse concolorous blotch at mid-dorsum; subapical fascia slender reaching beyond mid-termen. Cilia concolorous with ground colour. Hindwing cream, tinged pale orange in peripheries; cilia cream.

Male genitalia (Figs 5-7). Uncus rudimentary; socius large, tapering terminad, minutely spined in terminal part; terminal plate of gnathos long, spine-like; valva tapering posteriorly, rounded apically; costa long with short subterminal and dorsoterminal processes; sacculus broad, strongly bent, with large, curved terminal process; phallus mostly slender; a single slender, long cornutus present, typical curved cornutus absent; median part of transtilla atrophied.

Female unknown.

\section{Material examined}

Holotype male: "Brasil: M[inas]G[erais] Nova Lima 850 m, 25-17. XII. 1982, V.O. BECKER col; Col. BECKER 50318"; GS 22276. Paratypes four males, one with label as above but dated 1-3. IV. 1983, VOBC 50778; one from Telemaco Borba, Paraná (750 m, 13-19. X. 1995, VOBC 9777, GS 386 WZ, one from Camacan, Bahia, 600 m, 15. IX. 1995, VOBC 106344, and two from Linhares, Espirito Santo, 40 m,16-18. IX. 1001, VOBC 80868, GS 387 WZ.

\section{Remarks}

Judging from the above, data $C$. celyphana is widely distributed in Brazil mostly at lower altitudes $(40-850 \mathrm{~m})$. The terminal process of the sacculus is slender in all the specimens examined except for the holotype (Fig. 7). 


\section{Etymology}

The specific name refers to the facies and resting position of the moth; Greek - kelyphos, fruit husk.

\section{Chamelania auricoma Razowski \& Pelz, 2003}

Chamelania auricoma RAZOWSKI \& PeLZ, 2003, Nachr. ent. Ver. Apollo, N.S., 24(4): 204, figs 38, 39, 57, 91, 92. Type-locality: San Vincente, Macas, Morona-Santiago Prov., Ecuador.

\section{Remarks}

In the male genitalia, C. auricoma is similar to $C$. lutea but has a long, slender sacculus and broad socii. The female of $C$. auricoma is distinct in that it has two short, heavily spined sclerites in the postmedian part of the corpus bursae. In $C$. lutea these sclerites are finely spined.

\section{Chamelania lutea sp. $\mathbf{n}$.}

(Figs 8, 9, 15, 23)

\section{Diagnosis}

C. lutea is related to C. jaliscana but differs from it chiefly in having slender socii, a broad sacculus, no postbasal process of the valval costa; the proximal part of the sclerite of the corpus bursae is rounded.

\section{Description}

Wing span $11 \mathrm{~mm}$. Head yellowish cream, thorax darker. Forewing slightly expanding posterad; apex rounded; termen weakly oblique, hardly convex. Ground colour yellowish cream; suffusions indistinct. Markings darker than ground colour, more orange consisting of markings along veins and dorsum in basal area; median fascia consisting of three indistinct parts, stronger at tornus; almost parallel to a slender fascia followed by subapical curved, parallel marking extending from $3 / 4$ of costa to $1 / 3$ of termen where broadened. Cilia cream. Hindwing cream, anal area brownish; cilia pale cream and pale brownish.

Male genitalia (Figs 8, 9). Uncus atrophied; socius long, broad to beyond middle, constricted subterminally with terminal broadening; valva proportionately broad with triangular caudal part; costa strong, broadening subterminally, with small terminal process, without postbasal process; sacculus broad; right sacculus with large terminal process, left sacculus with shorter dorsoterminal process and small ventroposterior process; phallus broad, 
weakly expanding ventroterminally; one curved, strong cornutus, curved, the other slender, half length of the former.

Female genitalia (Fig. 15). Anteostial sterigma slightly concave in middle anteriorly, rounded laterally; ductus bursae stout with large sclerite extending to middle of corpus bursae.

\section{Material examined}

Holotype male: "Brasil: M[inas]G[erais], Unai, 700 m, 3. XI. 1983, V.O. BECKER col; Col. BECKER 49873"; GS 22042; Paratypes, identically labelled male (not dissected) and female (GS 22042)

\section{Etymology}

The specific name refers to the forewing colouration.

\section{Chamelania quasirufa sp. $\mathbf{n}$.}

(Figs 16, 24)

\section{Diagnosis}

C. quasirufa is closely related to $C$. lutea and externally similar to $C$. jaliscana but the latter has distinctly convex forewing costa. From $C$. lutea it differs in having a brown-grey not creamish hindwing, a laterally convex sterigma, and longer sclerites of the ductus bursae.

\section{Description}

Wing span $15 \mathrm{~mm}$. Head cream; vertex and thorax rust orange. Forewing not expanding posteriorly; costa almost straight; apex rounded; termen indistinctly convex. Ground colour orange cream; markings concolorous with thorax, typical of the genus; suffusions slightly paler than markings, developed in posterior half of wing and along dorsum. Cilia orange cream. Hindwing brown grey; cilia brownish cream.

Male unknown.

Female genitalia (Fig. 16). Sterigma broadest postmedially, extending laterally; sclerites of posterior part of corpus bursae and ductus bursae elongate, median fairly long, pointed; base of ductus seminalis membranous.

\section{Material examined}

Holotype female: "Brasil: RO[ndonia], Cacaulandia 140 m, XI. 1991; V.O. BECKER Col; Col. BECKER 80217”; GS 385 WZ. 


\section{Etymology}

The name refers to the forewing colouration; Latin: quasi - as if and rufa - red.

\section{Chamelania belemana sp. $\mathbf{n}$.}

(Figs 10, 11, 17, 25)

\section{Diagnosis}

The male genitalia of $C$. belemana can be distinguished by the atrophied processes of valva but the transtilla and the female genitalia resemble those of $C$. jaliscana. The female genitalia differ from those of $C$. jaliscana in the weaker sclerites of the corpus bursae.

\section{Description}

Wing span $12 \mathrm{~mm}$. Head and thorax yellowish cream, the latter tinged orange proximally. Forewing uniformly broad throughout, costa mostly straight. Ground colour yellow; markings pale orange typical of the genus. Cilia damaged [yellow]. Hindwing brownish grey, cilia grey.

Sexual dimorphism. Female. Wing span $13 \mathrm{~mm}$. Forewing broadest postmedially; costa convex. Ground colour yellow in basal part of wing tinged orange. Markings pale orange consisting of basal blotch, broad median fascia reaching dorsum, and broad subterminal fascia almost reaching tornus. Cilia yellow. Hindwing brownish tinged orange.

Male genitalia (Figs 10, 11). Uncus small on broad base; socius long, moderately broad proximally, very slender terminally, with apical spine; valva simple, upcurved; costa without processes; sacculus long, tapering terminally; median part of transtilla moderately large, subtriangular; phallus large; lobes of vesica densely thorny; cornutus inconspicuous.

Female (Fig. 17). Anteostial sterigma short, concave proximally; ductus seminalis short; sclerites of corpus bursae weak, lateroposterior one extending to middle of ductus bursae; base of ductus seminalis sclerotized.

\section{Material examined}

Holotype male: "Brasil: Pará, Belém 20 m, I. 1984, V.O. BECKER col”; Col. BECKER 47148"; not dissected. Paratypes identically labelled three males (one with GS 22278) and three females (one with GS 22282).

\section{Etymology}

The name refers to the type locality, Belém. 


\section{Chamelania xanthophilana (WALKER, 1863) comb. n.}

(Fig. 18)

Lophoderus xanthophilanus WALKER, 1863, List Specimens Lepid. Insects Colln. British Museum, 28: 335. Type locality: Ega, Brazil. NHML.

\section{Diagnosis}

In facies, $C$. xanthophilana is somewhat similar to $C$. belemana and $C$. acaena but $C$. xanthophilana has two forewing fasciae, median and postmedian, and atrophied posterior markings. The female genitalia are distinguished by the long, spinose sclerites of the corpus bursae.

\section{Description}

Wing span of holotype $14 \mathrm{~mm}$. Ground colour of forewing yellow, tinged pink postmedially. Markings orange rust, darkest in costal area; apex of wing rust brown. Cilia concolorous with ground colour, rust at apex. Hindwing rust orange, cilia paler.

Female genitalia: sterigma short, broad, straight proximally; ductus bursae short, mostly membranous; corpus bursae elongate, sclerites long, extending into base of ductus bursae, in major part densely spined; ductus seminalis posterior, broad, microspined basally.

\section{Material examined}

Only the holotype.

\section{Chamelania corumbae sp. $\mathbf{n}$.}

(Figs 19, 27)

\section{Diagnosis}

C. corumbae differs from all congeners in having brown forewing markings and brownish cream ground colour. Female genitalia similar to $C$. quasirufa and $C$. xanthophilana but differ from them in having a small sterigma and a curved sclerite of the corpus bursae without strong spinulation.

\section{Description}

Wing span $13 \mathrm{~mm}$. Head and thorax brownish cream. Forewing not expanding posteriorly; costa convex; termen straight, weakly oblique. Ground colour brownish cream. Markings brownish; dorsal marking diffused; median fascia weakly preserved in dorsal part of wing; subterminal fascia slender, bifid at costa. Cilia damaged. Hindwing brownish. 
Male unknown.

Female genitalia (Fig. 19). Sterigma broad, short, convex laterally before end of antevaginal part; sclerite of corpus bursae long extending between middle of ductus bursae and middle of corpus bursae; spinulation weak; ductus seminalis from posterior part of a basal sac.

\section{Material examined}

Holotype female: "Brasil: M[to Grosso do] S[ul], Corumba, 600 m, 20-22. IV. 1985, V.O. BECKER col; Col. BECKER 63959”; GS 53 Vd BECKER."

\section{Etymology}

The name refers to the type locality, Corumba.

\section{Odonthalitus RAZOWSKI, 1991}

Odonthalitus RAzOWSKI, 1991, SHILAP Revta lepid., 18: 208. Type species: Odonthalitus lacticus RAZOWSKI, 1991.

Odonthalitus and Lobogenesis RAZOWSKI, 1990 were revised by BROWN (2000) who stated that the male genitalia share several morphological characters. He reviewed them for the phylogenetic analysis and provided a cladogram of phylogeny for the two genera.

BROWN (2000) supposed that these genera may be synonymous but proposed "a conservative approach for the stability of the generic nomenclature of the group." I agree with BROWN (2000) in this respect and suggest that molecular studies should be additionally undertaken to solve the problem.

\section{Odonthalitus poas BROWN, 2000}

(Figs 12, 13, 26)

Odonthalitus poas Brown, 2000, Proc. Ent. Soc. Wash., 102: 45, figs 18, 26, 36. Type locality: Rio Aquiares, Cartago Province, Costa Rica.

\section{Description}

Wing span $10.5 \mathrm{~mm}$. Head and thorax grey, frons whitish. Forewing mostly expanding terminally; costa straight; termen indistinctly sinuate, somewhat oblique. Ground colour white, in terminal part of wing tinged grey, with sparse concolorous strigulation. Markings: basal 
blotch brown; costal triangle blackish. Cilia grey paler at mid-termen. Hindwing white strigulated grey.

Male genitalia (Figs 12,13) as described for the genus.

\section{Material examined}

Holotype male: "Costa Rica: Cruz, Turrialba 1500 m, VIII. 1981, V.O. BECKER col; Col. BECKER 45339”; GS $370 \mathrm{WZ}$.

\section{ACKNOWLEDGEMENTS}

The authors thank Mr Artur CZEKAJ, Kraków, for taking the photographs and arranging the plates. Special thanks are also due to Dr Łukasz PRZYBYŁOWICZ for his generous assistance, and to the two anonymous reviewers for their valuable comments.

\section{REFERENCES}

BROwN J.W. 2000. Revision of Lobogenesis Razowski and Odonthalitus RAzowsKI (Lepidoptera:

Tortricidae: Tortricinae) with comments on their monophyly. Proceedings of Entomological Society Washington, 102 (1): 21-49.

RAzowski J., Pelz V. 2003. Tortricidae collected in Ecuador in the years 1996-1999: Euliini (Lepidoptera). Nachrichten des Entomologischen Vereins Apollo, Neue Folge, 24(4): 189-207.

Received: 27 February 2018

Accepted: 5 July 2018 